Session 1531

\title{
Using a Delphi Study to Identify the Most Difficult Concepts for Students to Master in Thermal and Transport Science
}

\author{
Ruth A. Streveler, Barbara M. Olds, Ronald L. Miller ${ }^{1}$ \\ Colorado School of Mines \\ Mary A. Nelson \\ University of Colorado, Boulder
}

\begin{abstract}
In this paper, we describe the use of Delphi methodology to reach consensus among a group of experienced engineering faculty about the difficulty and importance of fundamental concepts in the thermal and transport sciences. Our purpose is to identify concepts of high importance and low student understanding to use as the focus for creating a concept inventory to assess students' conceptual understanding in the thermal and transport sciences. Based on the Delphi study results, 12 concepts are currently under consideration for inclusion in the concept inventory.
\end{abstract}

\section{Introduction and Background}

Engineering faculty members often comment that even students who can correctly solve problems in fluid dynamics, heat transfer, or thermodynamics still believe that, for example, heat flows like a substance or that processes stop when they reach equilibrium. These faculty observations are supported by evidence in the literature that suggests science and engineering students do not conceptually understand many fundamental molecular-level and atomic-level phenomena such as light, heat, or electricity. [1,2] The literature also suggests that the problem is more than simply one of confusion or misunderstanding, but instead involves fundamental misconceptions by students about differences in the way that molecular-scale processes differ from observable, macroscopic causal behavior we experience in our daily lives. [3, 4]

Before faculty can hope to develop curricular interventions to repair student misconceptions like these, they must first identify which concepts their students don't understand and what misconceptions are prevalent. Such assessments (termed concept inventories) are now available in selected science fields (e.g. physics, chemistry, biology, astronomy) and in some mathematics topics, but are only now being developed for selected engineering science topics. [5]

With NSF support, we are developing a concept inventory for thermal and transport sciences encompassing introductory thermodynamics, fluid mechanics, and heat transfer. To help validate our inventory, we have conducted a Delphi study with approximately 30 well-respected engineering faculty experts and prominent engineering textbook authors to identify important concepts in thermal and transport science disciplines that are consistently difficult for students to

\footnotetext{
${ }^{1}$ Contact author: Ronald L. Miller, Professor of Chemical Engineering, Colorado School of Mines, Golden, CO 80401, rlmiller@mines.edu, 303-273-3892.

Proceedings of the 2003 American Society for Engineering Education Annual Conference \& Exposition Copyright $(22003$, American Society for Engineering Education
} 
understand and for which the students possess significant and robust misconceptions. Once developed and validated, the concept inventory will be made available to interested engineering faculty for use as a classroom formative assessment tool that can provide valuable information about student misconceptions in thermal and transport science topics. This information can then be used by faculty to guide the selection of course topics and also to help decide what interventions are required to repair robust misconceptions that engineering students bring to new courses. The instrument may also be used as a program feedback assessment tool to monitor the overall persistence or absence of student misconceptions during a 4-5 year course of study.

The objectives of this paper are to:

1) describe the Delphi methodology and how we conducted a Delphi study to identify thermal and transport science concepts that were, in the judgment of the expert participants, difficult to learn but important for engineering students to understand.

2) present the results of the Delphi study and discuss the implications of our findings to developing a thermal and transport science concept inventory.

\section{What is the Delphi Method?}

The Delphi method is based on a structured process for collecting and distilling knowledge from a group of experts by means of a series of questionnaires interspersed with controlled opinion feedback. [6] Linstone and Turoff say that "Delphi may be characterized as a method for structuring a group communication process so that the process is effective in allowing a group of individuals, as a whole, to deal with a complex problem." [7] The method takes its name from the Oracle at Delphi, an ancient Greek soothsayer able to predict the future, and was originally developed at the RAND Corporation by Dalkey and Helmer [8] as a tool for forecasting likely inventions, new technologies and the social and economic impact of technological change. [6]

The distinguishing features of the Delphi technique are its use of experts and its methodology. Proponents of the Delphi method recognize human judgment as a legitimate and useful input in generating forecasts and therefore believe that the use of experts, carefully selected, can lead to reliable and valid results. In addition, the Delphi technique attempts to overcome the weaknesses implicit in other methods such as relying on a single expert, a group average, or a round table discussion. Using a single expert puts too much weight on one person's opinion; the group average method fails because as Clayton notes, "the individuals consulted have neither the opportunity to provide their most thoughtful input nor the benefit of hearing other responses that might encourage a refinement of the contributions" [9]; and the round-table approach is unreliable because some members of the group may unduly influence the decision. The Delphi method addresses the latter concern by soliciting input anonymously so that influences such as the professional reputation of a respondent or the forcefulness of a respondent's personality are neutralized. Thus all participants have equal stature in the process and their comments influence the other participants only through the logic of their argument, not their name recognition.

There have been criticisms of the Delphi method, most notably by Sackman [10], whose early critique found fault with many elements of the process, but particularly with what he considered

Proceedings of the 2003 American Society for Engineering Education Annual Conference \& Exposition Copyright $\mathbb{C} 2003$, American Society for Engineering Education 
to be the Delphi's failure to meet APA's "Standards for Educational and Psychological Tests and Manuals." Specifically, he concluded that "conventional Delphi neglects virtually every major area of professional standards for questionnaire design, administration, application, and validation." Despite Sackman's criticisms, we believe that the Delphi method is well-suited for our current project and we agree with Clayton's conclusion that "if the objective is the identification of content based on expert consensus, then the Delphi technique is an appropriate choice as it may enhance the significant contributions of the panel."

\section{General Outline of the Delphi Method}

According to Linstone and Turoff, "Usually Delphi, whether it be conventional or real-time, undergoes four distinct phases. The first phase is characterized by exploration of the subject under discussion, wherein each individual contributes additional information he [sic] feels is pertinent to the issue. The second phase involves the process of reaching an understanding of how the group views the issue (i.e., where the members agree or disagree and what they mean by relative terms such as importance, desirability, or feasibility). If there is significant disagreement, then that disagreement is explored in the third phase to bring out the underlying reasons for the differences and possibly to evaluate them. The last phase, a final evaluation, occurs when all previously gathered information has been initially analyzed and the evaluations have been fed back for consideration." [7]

\section{Our Application of the Delphi Process}

Panel Selection. Since the Delphi method relies on expert opinion, it is obviously important to select the right experts. In some cases, Delphi participants are selected through a "nomination" process in which recognized experts are solicited but also asked to provide the names of other experts. [11] Selection criteria should be clearly articulated, e.g. number of years of experience, number of publications or other expert qualifications. For our panel, we started with a geographically distributed list of people with expertise in the appropriate fields and considerable undergraduate teaching experience. We asked these experts to help us identify others, including textbook authors in the relevant fields. Once we had identified approximately 35 experts, we sent them an email explaining the Delphi process and our project along with an invitation to join the group. Thirty-one experts agreed to participate, a number corresponding well with Clayton's ruleof-thumb that 15-30 people are an adequate panel size. [9] The group included tenured and tenure-track engineering professors from research universities and undergraduate institutions. Five of the participants have authored well-known texts in thermodynamics, fluid mechanics, heat transfer, or thermal science. We guaranteed confidentiality for all participants during the process, another important element of the Delphi procedure.

Round 0. We wanted our expert panel to generate a list of difficult concepts in thermal and transport science rather than generate one ourselves. Therefore, we developed a "Round 0" for our project in which we asked panelists to list concepts they found difficult for their students. Of the 31 experts who agreed to participate in the study, 23 provided approximately 60 separate concepts. Four researchers coded all the responses and developed a list of 28 separate concepts by including all concepts that had been listed by at least two of our experts. These 28 concepts

Proceedings of the 2003 American Society for Engineering Education Annual Conference \& Exposition Copyright $\mathbb{C} 2003$, American Society for Engineering Education 
formed the basis for our subsequent rounds.

Round 1. We developed both a web-based and a Word document version of our questionnaire using the 28 concepts generated in Round 0 . We asked each expert to rate each concept based on two factors: 1) the proportion of students that do understand the concept and 2) how important it is for a student to understand the concept. We used a scale of $0-10$ for each question $(0=$ no one understands this concept to $10=$ everyone understands this concept, and $0=$ it is not at all important to understand this concept to $10=$ it is extremely important to understand this concept). Thirty members of our expert panel ranked these 28 concepts. In all rounds, participants were told that "you will not have to rate any concept for which you don't feel you have sufficient expertise."

Round 2. For the second round of the questionnaire (again in both a web and Word attachment version), we presented the panel of experts with the same concepts and asked them to rank the concepts using the same scale. However, we also provided them with the median response to each question from Round 1 and a range that included $50 \%$ of the responses from Round 1 . In the second round, if they rated a concept outside of the 2-quartile range established in round 1 , they were asked to provide an explanation for their rating. In this way, the median ranking of each concept approached a stable value and the interquartile range decreased in size, representing the consensus opinion of the participant group. Twenty-eight members of our expert panel ranked the 28 concepts in round 2 .

Round 3. In the third round, we again asked the experts to rank all 28 concepts. We provided the median rating from Round 2 and the anonymous comments that fellow panelists made justifying ratings outside of the specified range. Based on this final iteration, we selected 12 of the most common and most important concepts in the thermal and transport sciences to develop questions for the thermal and transport science concept inventory.

\section{Results and Discussion}

Based on responses from 30 participants for round 1 and 28 participants in round 2, we computed the ranking statistics for each of the 28 concepts in the study. These results are summarized in Table I. The non-parametric median and interquartile range were used (rather than mean and standard deviation) because an ordinal scale was used to rate the concepts. These results indicate that the rankings for most concepts have already stabilized (the median for 19 of the 28 concepts changed by a value of 0.5 or less) and we expect results from the $3^{\text {rd }}$ and final round, which will be completed and analyzed in time for presentation at ASEE 2003, will provide a stable consensus for nearly all the concepts in the study in agreement with the Delphi literature.

Figure 1 illustrates the relationship between concept understanding and importance using the results of round 2 . The region of high importance but low conceptual understanding includes a total of 12 concepts which the study participants judge to be sufficiently important to engineering graduates that conceptual understanding is crucial but often not achieved. These 12 items include key topics in thermal science and transport courses such as the $2^{\text {nd }}$ law of thermodynamics including reversible vs. irreversible processes, conservation of momentum, viscous momentum

Proceedings of the 2003 American Society for Engineering Education Annual Conference \& Exposition Copyright $\mathbb{C} 2003$, American Society for Engineering Education 
transfer, several energy-related topics (heat, temperature, enthalpy, internal energy), and steadystate vs. equilibrium processes. Many of these concepts have been widely discussed in the misconception literature [12], thus lending a degree of validity to the results of this study.

\section{Table I - Ranking Results from Delphi Study Rounds 1 and 2 (Italicized concepts refer to low understanding/high importance rankings shown in Figure 1)}

\begin{tabular}{|l|c|c|c|c|}
\hline \multirow{2}{*}{ Concept } & \multicolumn{2}{|c|}{$\begin{array}{c}\text { Understood? } \\
\text { Median (Interquartile range) }\end{array}$} & \multicolumn{2}{c|}{$\begin{array}{c}\text { Importance? } \\
\text { Median (Interquartile range) }\end{array}$} \\
\hline & Round 1 & Round 2 & Round 1 & Round 2 \\
\hline 1.Adiabatic vs. Isothermal Processes & $7.5(6-8)$ & $8(6-8)$ & $9(8-10)$ & $9(9-10)$ \\
\hline 2.Bernoulli Equation & $7(4-8)$ & $6(5-7)$ & $9(7-10)$ & $9(8-9)$ \\
\hline 3. Compressible vs. Incompressible Flow & $5(3-7)$ & $6(4-6.5)$ & $7.5(6-8)$ & $7(7-8)$ \\
\hline 4. Conservation of Linear Momentum & $5(3-6)$ & $5(4-6)$ & $9(8-10)$ & $9(8-10)$ \\
\hline 5. Differential vs. Integral Analysis & $4.5(3-6)$ & $4(3-5.25)$ & $7(6-9)$ & $8(6-8)$ \\
\hline 6. Dimensional Analysis & $6(4-7)$ & $5.5(4.25-7)$ & $7(5-7)$ & $6(5-8)$ \\
\hline 7. Entropy \& 2nd Law of Thermodynamics & $4(2-6)$ & $4(3-5)$ & $8(7-9)$ & $9(8-9)$ \\
\hline 8. Extensive and Intensive Properties & $8(6-9)$ & $8(7-8)$ & $7(6-9)$ & $8(7-9)$ \\
\hline 9. First Law of Thermodynamics & $8(7-9)$ & $8(7-9)$ & $10(10-10)$ & $10(10-10)$ \\
\hline 10. Fluid vs. Flow Properties & $7(5-8)$ & $6(5-7)$ & $7(5-9)$ & $7(5-8)$ \\
\hline 11. Heat Transfer Modes & $8(6-9)$ & $8(6.25-8)$ & $9(8-10)$ & $9(9-10)$ \\
\hline 12. Heat vs. Energy & $6(5-8)$ & $6(5-7)$ & $9(8-10)$ & $9(8-10)$ \\
\hline 13. Heat vs. Temperature & $6(4-8)$ & $6.5(5-8)$ & $9(8-10)$ & $10(9-10)$ \\
\hline 14. Ideal Gas Law & $8(7-9)$ & $8(8-9)$ & $9(8-10)$ & $9(9-10)$ \\
\hline 15. Internal Energy vs. Enthalpy & $6(3-7)$ & $5(4-6)$ & $8(7-9)$ & $9(8-9)$ \\
\hline 16. No-slip Boundary Conditions & $8(6-9)$ & $8(7-9)$ & $8(7-9)$ & $9(8-9)$ \\
\hline 17. Nozzles and Diffusers & $6(5-8)$ & $6(6-7.5)$ & $7(5-9)$ & $7(6-8)$ \\
\hline 18. Pressure & $8(6-9)$ & $8(7-8)$ & $9(8-10)$ & $10(9-10)$ \\
\hline 19. Reversible vs. Irreversible Processes & $5(4-7)$ & $5(4-6)$ & $8(8-9)$ & $9(8-9)$ \\
\hline 20. Spatial Gradient of a Function & $4(3-7)$ & $5(4-6)$ & $7(3-9)$ & $7(6-8)$ \\
\hline 21. Specific Heat Capacity & $7(6-8)$ & $7(6-7)$ & $8(7-10)$ & $9(8-9)$ \\
\hline 22. Steady-state vs. Equilibrium Process & $5(3-8)$ & $5(3-6)$ & $8(5-10)$ & $9(7-9)$ \\
\hline 23. Steady-state vs. Unsteady-state Process & $8(7-8)$ & $8(7-8)$ & $9(8-10)$ & $9.5(9-10)$ \\
\hline 24. System vs. Control Volume & $7(4-8)$ & $6(5-7)$ & $8(6-10)$ & $9(8-10)$ \\
\hline 25. Temperature Scales & $7(5-9)$ & $8(8-9)$ & $8(6-10)$ & $9(8-10)$ \\
\hline 26. Thermal Radiation & $6(4-8)$ & $5(5-6)$ & $7(5-9)$ & $8(6.75-8)$ \\
\hline 27. Thermodynamic Cycles & $7(5-8)$ & $7(6-7)$ & $8(8-10)$ & $9(8-10)$ \\
\hline 28. Viscous Momentum Flux & $5(3-7)$ & $4(3.75-5)$ & $7.5(6-9)$ & $8(7-8)$ \\
\hline & & & & \\
\hline
\end{tabular}

\begin{tabular}{|c|c|}
\hline Understanding scale & Importance scale \\
\hline $0=$ no one understands the concept & $0=$ Not at all important to understand the concept \\
\hline $10=$ everyone understands the concept & $10=$ Extremely important to understand the concept \\
\hline
\end{tabular}

Proceedings of the 2003 American Society for Engineering Education Annual Conference \& Exposition Copyright C2003, American Society for Engineering Education 


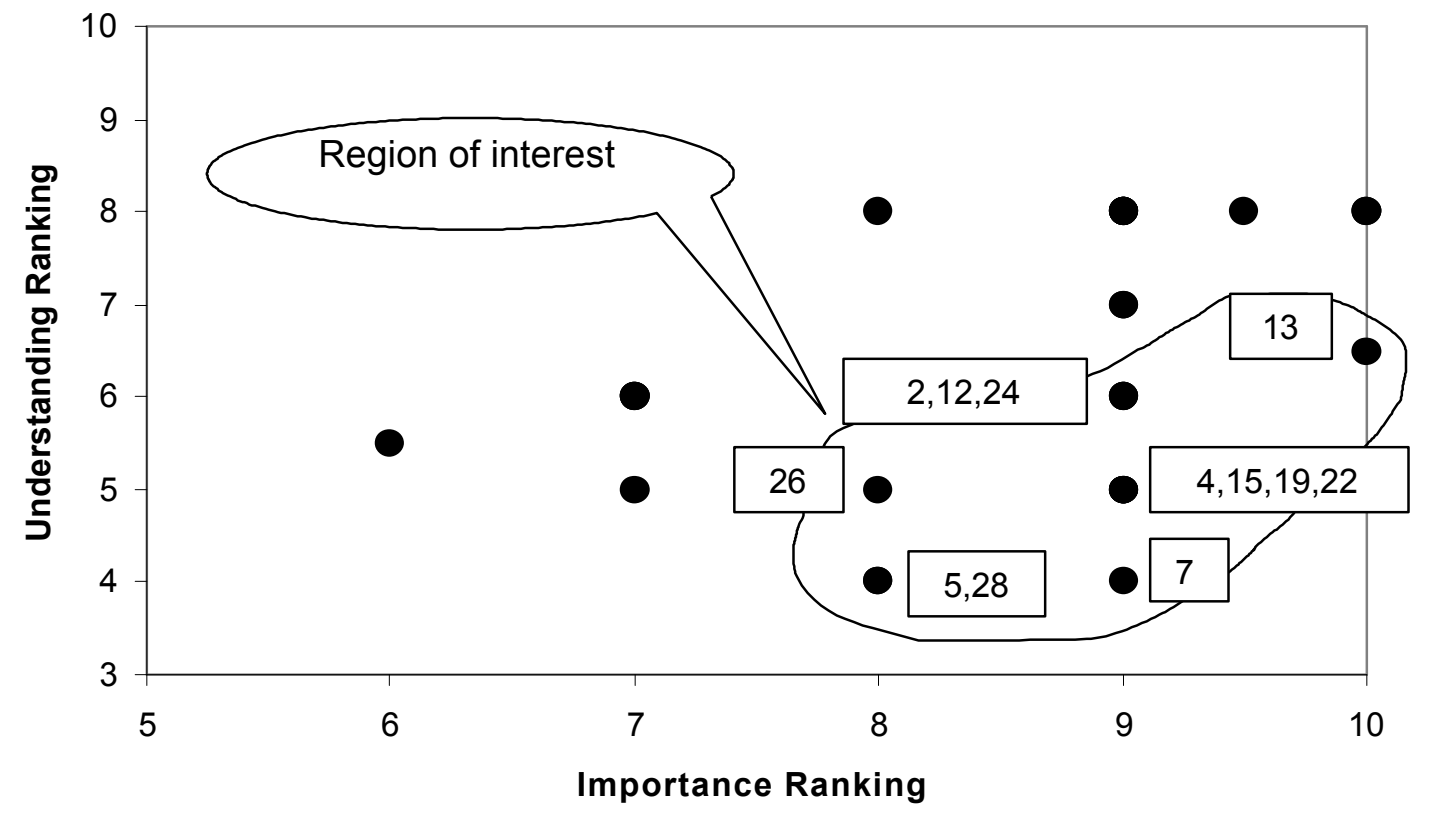

\section{Figure 1 - Relationship Between Delphi concept Understanding and Importance Rankings (Results at the end of Round 2); Numbers shown refer to concept numbers listed in Table I}

Results from the Delphi study will form the basis for constructing our thermal and transport science concept inventory and will allow us to create an assessment instrument focused on the most important concepts for which students have difficulty achieving a deep conceptual understanding. For example, concept \#7 (entropy and the $2^{\text {nd }}$ law of thermodynamics) was rated a " 4 " in student understanding but a " 9 " in importance, so several questions in the inventory will deal with $2^{\text {nd }}$ law constraints on system efficiency and the tendency for increasing disorder. Without the results reported in this paper, we easily could have wasted valuable time and money developing a concept inventory which dealt with the wrong concepts or concepts for which student assessment data are not needed or warranted.

\section{Summary and Conclusions}

We have conducted a Delphi ranking process to identify key concepts for use in a new concept inventory for thermal and transport sciences. Thirty-one technical and education experts in thermodynamics, fluid mechanics, and heat transfer have ranked a list of 28 concepts in two ways - the degree to which undergraduate engineering students understand each concept and how important the concept is for students to know. After three Delphi rounds, we will have identified 
by consensus the most significant concepts for use in a concept inventory.

Delphi methodology is used here for the first time to reach expert consensus about fundamental concepts in an engineering discipline. We believe the results of this study support the use of the Delphi technique for this purpose. The methodology dictates that three iterations of surveys be used to reach rating stability and we found that there was only a small fluctuation of median ratings between rounds 1 and 2 with a trend toward decreased variability of ratings. This demonstrates a move toward consensus in the ratings.

Graphical representation of understanding and importance ratings also allowed us to identify 12 concepts that are the best candidates to be included in a concept inventory (since we want the inventory to focus on important concepts that are difficult to understand). Without the results reported in this paper to identify the key conceptual stumbling blocks for undergraduate engineering students, we easily could have wasted valuable time and money developing a concept inventory which dealt with the wrong concepts or concepts for which student assessment data are not needed or warranted.

\section{Acknowledgment}

We acknowledge the financial support of the National Science Foundation for this work (project DUE-0127806).

\section{References}

1) Reiner, M., Slotta, J.D., Chi, M.T.H., and Resnick, L.B., "Naive Physics Reasoning: A Commitment to Substance-Based Conceptions," Cognition and Instruction, 18(1), 1-34, 2000.

2) Garnett, P.J., and Hackling, M., "Students' Alternative Conceptions of Chemistry: A Review of Research and Implications for Teaching and Learning," Studies in Science Education, 25, 69, 1995.

3) Chi, M.T.H., Slotta, J.D., de Leeuw, N, "From Things to Processes: A Theory of Conceptual Change for Learning Science Concepts," Learning and Instruction, 4, 27-43, 1994.

4) Chi, M.T.H, and R.D. Roscoe, "The Processes and Challenges of Conceptual Change," in Reframing the Process of Conceptual Change: Integrating Theory and Practice, Limon, M. and Mason, L., eds., Kluwer Academic Publishers, The Netherlands, 2002.

5) Evans, D.L., "Tools for Assessing Conceptual Understanding in the Engineering Sciences," Proceedings of the Frontiers in Education Conference, Boston, Massachusetts, November 6-9, 2002.

6) Adler, M. and Ziglio, E., eds., Gazing into the Oracle: The Delphi Method and its Application to Social Policy and Public Health, Jessica Kingsley Publishers, London, 1996.

7) Linstone, H. A. and Turoff, M., eds., The Delphi Method: Techniques and Applications, Addison-Wesley Publishing Company, Reading, MA, 1975. Also available at http://www.is.njit.edu/pubs/delphibook/ch1.html

Proceedings of the 2003 American Society for Engineering Education Annual Conference \& Exposition Copyright $\mathbb{C} 2003$, American Society for Engineering Education 
8) Dalkey, N. and Helmer, O., "An Experimental Application of the Delphi Method to the Use of Experts," Management Science, 9, 458-467, 1963.

9) Clayton, M. J., "Delphi: A Technique to Harness Expert Opinion for Critical DecisionMaking Tasks in Education," Educational Psychology, 17 (4), 373-386, 1997.

10) Sackman, H., Delphi Critique: Expert Opinions, Forecasting, and Group Process, D. C. Heath, Lexington, MA, 1975.

11) Fish, L. S. and Busby, D.M., "The Delphi Method," in Research Methods in Family Therapy., Prenkl, D.H. and Moon, S.M., eds., The Guilford Press, NY, pp. 469-482, 1996.

12) Pfundt, H. \& Duit, R., Bibliography: Students' Alternative Frameworks and Science Education, $4^{\text {th }}$ edition, Institute for Science Education, Keil, Germany, 1994.

\section{Biographical Information}

RUTH A. STREVELER is the Director of the Center for Engineering Education and the Director of Academic Services at the Colorado School of Mines. Dr. Streveler received her Ph.D. in Educational Psychology from the University of Hawaii at Manoa. She also holds a Master of Science in Zoology from the Ohio State University and a Bachelor of Arts in Biology from Indiana University at Bloomington. She is co-director of an NSF-sponsored project to develop assessment instruments for identifying misconceptions in engineering students. She is also a coprincipal investigator for the Center for the Advancement of Engineering Education that was recently funded by NSF. Her paper entitled "Investigating Student Misconceptions in the Design Process Using Multidimensional Scaling," was a finalist for the Educational and Research Methods Division best paper award for the 2001 ASEE national conference.

BARBARA M. OLDS is Associate Vice President for Academic Affairs and Professor of Liberal Arts and International Studies at the Colorado School of Mines where she has been a member of the faculty for the past nineteen years. Dr. Olds has received the Brown Innovative Teaching Grant and Amoco Outstanding Teaching Award at CSM and was the CSM Faculty Senate Distinguished Lecturer for 1993-94. She also received the Helen Plants Award for Best Workshop at the 1992 Frontiers in Education national conference and was awarded a Fulbright fellowship to teach and conduct research in Sweden during the 1998-99 academic year. She has received grant awards from NSF, FIPSE, NEH, and the Colorado Commission on Higher Education.

RONALD L. MILLER is Professor of Chemical Engineering and Petroleum Refining at the Colorado School of Mines where he has taught chemical engineering and interdisciplinary courses and conducted research in educational methods for over seventeen years. He has received three university-wide teaching awards and has held a Jenni teaching fellowship at CSM. His paper entitled "Connections: A Longitudinal Study of an Integrated Freshman Program" (co-authored with Barbara Olds) won the award for best paper in the Educational and Research Methods Division of ASEE during the 2001 annual conference. He has received grant awards for educational research from the National Science Foundation, the U.S. Department of Education, the National Endowment for the Humanities, and the Colorado Commission on Higher Education.

MARY A. NELSON is a PhD candidate in the Research and Evaluation Methods program at the University of Colorado, Boulder working with Dr. Lorrie Shepard. Mary has taught math at the middle school, high school, and college levels for nearly 35 years and is presently conducting research on two funded grants studying how middle school students learn algebra and assessing engineering student misconceptions in thermal and transport sciences.

Proceedings of the 2003 American Society for Engineering Education Annual Conference \& Exposition Copyright $(\mathrm{C} 2003$, American Society for Engineering Education 